\title{
PENGGUNAAN ATRAKTAN ASAM KLOROGENAT PADA PERANGKAP DALAM MENGENDALIKAN PBKo (Hypothenemus hampei Ferr.) PADA PERKEBUNAN KOPI DI KABUPATEN DAIRI
}

\author{
The Utilization of Chlorogenic Acid Attractant in Traps to Controlling PBKo (Hypothenemus hampei Ferr.) \\ on Coffee Plantation in Dairi".
}

\author{
M MUSTAIN AZIZ*, AMEILIA ZULIYANTI SIREGAR, HASANUDDIN \\ Program Studi Agroekoteknologi, \\ Fakultas Pertanian, Universitas Sumatera Utara \\ Medan 20155 \\ Email : mustainaziz31@gmail.com
}

\begin{abstract}
Coffee Fruit Borer (CFB) (Hypothenemus hampei) is an important pest that attacks the coffee fruit in coffee plantation. For the control by application of chemical pesticides ineffective, accordinglyit require to carry out the other control measures such as by trapping a flying female insect utilisingan attractant from natural ingredients that is around the farmer one such as chlorogenic acid compounds in coffee fruit. This research aims to determine the effectiveness of coffee fruit extract utilization for control of CFB. This research was conducted in Dairi district, North Sumatera on October until November 2016. This research used a non factorial randomized block design with 5 treatments. The results showed that the highest CFB trapped from SiRK4 at Sidikalang location on Robusta coffee with $100 \mathrm{~mL}$ of chlorogenic acid by 42.2 individuals and the treatment (SuRK4) at Sumbul location with Robusta and $100 \mathrm{mLof}$ chlorogenic acid was the best treatment to reduce the percentage of CFB attack. The percentage of CFB attack with air humidity shows significance at $F=0,018, p<0.05$ and air temperature with $F=0,030, p, 0.05$, where both of these factors greatly influence the percentage of CFB attack. While Pearson Correlation value analisys between moisture and percentage of attack that is $r=1,000^{*}$, show the higher of moisture hence will be higher percentage of attack. CFB control measures are carried out by trapping female flying insects utilising an attractant so that the population of CFB in the coffee plantation will be reduced.
\end{abstract}

Keywords: Control, Chlorogenic Acid, CFB

\section{PENDAHULUAN}

Kopi merupakan sumber minuman yang banyak dikonsumsi oleh masyarakat Indonesia. Provinsi Sumatera Utara merupakan salah satu daerah penghasil kopi di Indonesia terutama Kabupaten Dairi. Kabupaten Dairi memproduksi dua jenis kopi yaitu Arabica dan Robusta (Khairati, 2012). Produktivitas kopi Sumatera Utara lebih rendah dibandingkan dengan produktivitas kopi di negara lain. Produktivitas kopi arabica Sumatera Utara hanya 1.154 $\mathrm{kg} / \mathrm{ha} /$ tahun sedangkan Costa Rica 1.610 $\mathrm{kg} / \mathrm{ha}$ /tahun. Produktivitas Robusta 649 $\mathrm{kg} / \mathrm{ha} /$ tahun dibandingkan Laos $738 \mathrm{~kg} / \mathrm{ha} /$ tahun. Produktivitas yang rendah tersebut disebabkan oleh rendahnya masukan pupuk, kurangnya pemeliharaan tanaman, tidak adanya tanaman penaung, tuanya umur tanaman, dan tingginya serangan hama Penggerek Buah Kopi (PBKo) (Malau,2012).
Salah satu hama penting tanaman kopi adalah Penggerek Buah Kopi (PBKo) (Hypothenemus hampeI) yang menyerang buah kopi mulai dari buah yang masih hijau, matang susu sampai pasca panen. Dalam penerapan PHT, pengamatan terhadap OPT dan faktor lingkungan yang mempengaruhi perkembangan OPT harus dilakukan secara rutin (periodik) pada suatu areal pertanaman dengan menggunakan metode tertentu untuk mengumpulkan informasi tentang keadaan populasi atau tingkat serangan OPT serta faktorfaktor yang mempengaruhinya (Syahnen et.al., 2009).

Pengendalian dengan insektisida kimia tidak efektif karena hampir semua stadium perkembangan serangga hama tersebut berada di dalam buah. Disamping itu petani mengalami kendala di dalam penyemprotan karena pada umumnya ketinggian pohon kopi melebihi tinggi manusia (Laila et.al.,2011). Oleh karena itu 
Penggunaan Atraktan Asam Klorogenat sebagai Perangkap PBKo (Aziz, dkk)

diperlukan alterantif teknologi dalam pengendalian PBKo melalui deteksi komposisi dan 
konsentrasi senyawa kimia yang terdapat dalam buah kopi. Di dalam biji kopi terkandung beberapa senyawa kimia antara lain, kafein, trigoneline, protein, karbohidrat, asam alifatik, asam klorogenat, lemak, glikosida, mineral, dan komponen volatil (Embriani, 2014). Asam klorogenat selain bertindak sebagai antioksidan pada manusia, juga bersifat menarik serangga (Renwick and Chew, 1994).

Upaya pengendalian PBKo dilakukan dengan cara menangkap serangga betina yang terbang menggunakan senyawa penarik (atraktan) sehingga populasi $H$. hampei di pertanaman akan berkurang. Kesulitan petani memperoleh atraktan dari bahan buatan pada saat dibutuhkan perlu diatasi dengan mencari atraktan dari bahan-bahan alami lokal sebagai pengganti atraktan dari bahan-bahan buatan. Mengingat kesulitan tersebut, maka perlu dicari atraktan alternatif yang berasal dari bahanbahan nabati alami yang ada disekitar petani. Bahan-bahan nabati alami ramah lingkungan tersebut diharapkan dapat berfungsi sebagai atraktan pada perangkap PBKo (Wiryadiputra, 2014). Penelitian ini bertujuan untuk mengetahui efektivitas pemanfaatan atraktan asam klorogenat terhadap pengendalian hama penggerek buah kopi.

\section{BAHAN DAN METODE}

Penelitian ini dilakukan di 4 lokasi perkebunan kopi masyarakat di Kabupaten Dairi. Identifikasi hama di Laboratorium Hama dan Penyakit Tumbuhan Fakultas Pertanian Universitas Sumatera Utara. Penelitian dimulai pada bulan Oktober 2016 sampai dengan November 2016.

Bahan yang digunakan dalam penelitian ini adalah ekstrak biji kopi sebanyak $1 \mathrm{~kg}$ masing-masing bahan dari varietas arabika dan robusta, tanaman kopi arabika dan robusta, larutan ekstrak asam klorogenat, aquadest, lembar perekat, kain kasa, kantongan plastik, dan deterjen.

Alat yang digunakan dalam penelitian ini adalah timbangan, mortal, erlenmeyer, toples plastik, blender, botol tabung, botol plastik ukuran $600 \mathrm{ml}$, gelas ukur,dan cutter.

Penelitian menggunakan rancangan acak kelompok (RAK) non faktorial dengan 5 perlakuan, yaitu : K0 (Kontrol, Aquadest), K1 (Atraktan asam klorogenat $25 \mathrm{ml}$ ), K2 (Atraktan asam klorogenat $50 \mathrm{ml}$ ), $\mathrm{K} 3$ (Atraktan asam klorogenat $75 \mathrm{ml}$ ), K4 (Atraktan asam klorogenat $100 \mathrm{ml}$ ).

\section{Peubah Amatan \\ Jumlah PBKo Yang Terperangkap Pada Perangkap}

Dihitung jumlah Imago PBKo yang terdapat pada perangkap yang telah dipasang. Perhitungan ini dilakukan secara manual.

\section{Tingkat Serangan Terhadap Buah Pada Pohon Yang Diamati}

Pengamatan dilakukan dengan mengambil seluruh buah kopi yang sudah mengeras hingga matang yang berada disekitar perangkap. Buah yang tergolong terserang memiliki ciri-ciri yaitu pada bagian bawah buah terdapat lubang bekas gerekan dan apabila dibuka bagian daging buah busuk dan berwarna hitam serta terdapat PBKo didalamnya. Kemudian dihitung persentase serangan Penggerek Buah Kopi dengan menggunakan rumus:

$$
\begin{gathered}
\mathrm{P}=\mathrm{a} / \mathrm{b} \times 100 \% \\
\mathrm{P}=\text { Persentase buah yang terserang } \\
\mathrm{a}=\text { Jumlah buah yang terserang } \\
\mathrm{b}=\text { Jumlah Total buah yang diamati }
\end{gathered}
$$

\section{Pengukuran Faktor Fisik di Lingkungan Perkebunan Kopi}

Pengukuran Fisik yaitu mengukur Suhu udara, kelembapan, dan curah hujan.

\section{HASIL DAN PEMBAHASAN}

\section{Persentase Serangan PBKo dan Jumlah PBKo Terperangkap}

Dari hasil penelitian penggunaan atraktan asam klorogenat terhadap jumlah PBKo ( $H$. hampel) yang terperangkap menunjukkan hasil yang signifikan yaitu dengan nilai sig.0,002 pada anova. Dan pada persentase serangan juga signifikan yaitu dengan nilai $($ sig. $=0,000)$ pada uji anova.

Dari hasil perhitungan dengan 6 kali pengambilan sampel, jumlah PBKo ( $H$. hampel) yang terperangkap di dalam botol perangkap dengan jumlah tertinggi yaitu pada lokasi Sidikalang pada jenis kopi Robusta dengan perlakuan asam klorogenat sebanyak $100 \mathrm{ml}$ (SiAK4) dengan rataan jumlah PBKo terperangkap 42.2 individu (Tabel 1). Perlakuan ini merupakan perlakuan terbaik dalam meningkatkan jumlah PBKo terperangkap dengan penggunaan atraktan asam klorogenat. 
Hal ini menunjukkan bahwa asam klorogenat terbukti efektif untuk dimanfaatkan sebagai atraktan yang dapat merangsang serangga dalam pengendalian hama penggerek buah kopi (H. hampei). Firmansyah et.al., (2013) menyatakan bahwa senyawa chlorogenic acid (asam klorogenat) merupakan senyawa metabolit sekunder yang dapat merangsang serangga untuk meletakkan telur.

Tabel 1. Total PBKo terperangkap dan Persentase Serangan PBKo

\begin{tabular}{ccc}
\hline Perlakuan & $\begin{array}{c}\text { Rataan Jumlah PBKo } \\
\text { Terperangkap }\end{array}$ & Persentase Serangan (\%) \\
\hline SiAK0 & $35.0^{\text {cd }}$ & $65.6^{\mathrm{a}}$ \\
SiAK1 & $32.6^{\mathrm{d}}$ & $63.8^{\mathrm{ab}}$ \\
SiAK2 & $31.0^{\mathrm{de}}$ & $56.6^{\mathrm{abc}}$ \\
SiAK3 & $36.6^{\mathrm{bcd}}$ & $48.6^{\mathrm{bc}}$ \\
SiAK4 & $42.2^{\mathrm{a}}$ & $41.0^{\mathrm{c}}$ \\
SiRK0 & $29.6^{\mathrm{de}}$ & $64.4^{\mathrm{ab}}$ \\
SiRK1 & $38.4^{\mathrm{bc}}$ & $50.2^{\mathrm{abc}}$ \\
SiRK2 & $40.0^{\mathrm{b}}$ & $54.0^{\mathrm{abc}}$ \\
SiRK3 & $40.6^{\mathrm{ab}}$ & $56.6^{\mathrm{abc}}$ \\
SiRK4 & $35.4^{\mathrm{bcd}}$ & $46.8^{\mathrm{c}}$ \\
SuAK0 & $31.0^{\mathrm{de}}$ & $5.6^{\mathrm{d}}$ \\
SuAK1 & $29.0^{\mathrm{de}}$ & $3.4^{\mathrm{d}}$ \\
SuAK2 & $26.8^{\mathrm{de}}$ & $3.6^{\mathrm{d}}$ \\
SuAK3 & $29.4^{\mathrm{de}}$ & $4.6^{\mathrm{d}}$ \\
SuAK4 & $27.6^{\mathrm{de}}$ & $4.6^{\mathrm{d}}$ \\
SuRK0 & $22.6^{\mathrm{d}}$ & $5.0^{\mathrm{d}}$ \\
SuRK1 & $27.8^{\mathrm{de}}$ & $4.8^{\mathrm{d}}$ \\
SuRK2 & $24.0^{\mathrm{e}}$ & $3.4^{\mathrm{d}}$ \\
SuRK3 & $33.0^{\mathrm{d}}$ & $4.8^{\mathrm{d}}$ \\
SuRK4 & $33.4^{\mathrm{dd}}$ & $3.0^{\mathrm{d}}$ \\
\hline
\end{tabular}

Catatan: $\mathrm{Si}=$ Sidikalang; $\mathrm{Su}=\mathrm{Sumbul}$; $\mathrm{K} 0=\mathrm{Kontrol}$ (air); $\mathrm{K} 1=$ Ekstrak Klorogenat $(25 \mathrm{ml}) ; \mathrm{K} 2=$ Ekstrak Klorogenat $(50 \mathrm{ml}) ; \mathrm{K} 3=$ Ekstrak Klorogenat $(75 \mathrm{ml}) ; \mathrm{K} 4=$ Ekstrak Klorogenat $(100 \mathrm{ml}) ; \mathrm{R}=$ Robusta; $\mathrm{A}=$ Arabika; $\mathrm{S}=$ Ulangan dalam sampel.

Jumlah PBKo terperangkap paling rendah yaitu perlakuan kontrol pada lokasi Sumbul dengan jenis kopi Robusta (SuRKO) yaitu dengan rataan jumlah PBKo terperangkap 22.6 individu (Tabel 1). Hal ini menunjukkan bahwa adanya perangkap tanpa perlakuan atraktan kurang menarik bagi PBKo sehingga jumlah PBKo terperangkap hanya sedikit sehingga dapat dikatakan bahwa perangkap PBKo akan efektif jika ada atraktan sebagai senyawa penariknya. Menurut Nugroho (2015) atraktan pengendali hama Penggerek Buah Kopi (PBKo) merupakan alat perangkap yang terdiri atas dua bagian utama yaitu alat perangkap dan senyawa penarik (antraktan).

Persentase serangan terendah pada lokasi Sumbul dengan jenis kopi Robusta dan penggunaan atraktan asam klorogenat sebanyak $100 \mathrm{ml}$ (SuRK4) sebesar $3 \%$ dan persentase serangan tertinggi yaitu pada lokasi Sidikalang dengan jenis kopi Arabika dan tanpa penggunaan atraktan asam klorogenat (kontrol) (SiAK0) yaitu sebesar $65.6 \%$. Hal ini menunjukkan bahwa atraktan asam klorogenat pada perangkap mampu mengurangi jumlah populasi PBKo sehingga serangan PBKo pun 
menjadi rendah, akan tetapi keefektifan asam klorogenat juga dipengaruhi oleh faktor lain yang mempengaruhi adanya serangan PBKo salah satunya adalah pengaruh lingkungan, seperti tanaman yang terlalu rimbun, kelembaban,dan lain sebagainya. Perkembangan hama PBKo $(H$. hampeii) dipengaruhi oleh suhu optimum imago adalah $27^{\circ} \mathrm{C}-30^{\circ} \mathrm{C}$, kemudian naungannya terlalu padat (rapat) sehingga menghasilkan kelembaban tinggi, dan ketersediaan buah kopi (pasokan buah terus menerus dari generasi ke generasi). Diasumsi kan kelembaban yang tinggi akan mempengaruhi peningkatan populasi PBKo di pertanaman kopi, Siregar (2016).

Tabel 2. Uji Korelasi hubungan penggunaan atraktan asam klorogenat terhadap persentase serangan PBKo dengan faktor lingkungan

\begin{tabular}{|c|c|c|c|c|c|}
\hline & & $\begin{array}{l}\text { Persentase } \\
\text { serangan }\end{array}$ & Curah hujan & $\begin{array}{c}\text { Kelembaban } \\
\text { udara }\end{array}$ & Suhu udara \\
\hline \multirow{3}{*}{$\begin{array}{l}\text { Persentase } \\
\text { serangan }\end{array}$} & Pearson Correlation & 1 &,- 921 & $1,000^{*}$ & \multirow[t]{3}{*}{$\begin{array}{l}\text { Persentase } \\
\text { serangan }\end{array}$} \\
\hline & Sig. (2-tailed) & & ,254 & ,018 & \\
\hline & $\mathrm{N}$ & 100 & 3 & 3 & \\
\hline \multirow[b]{2}{*}{ Curah hujan } & Pearson Correlation &,- 921 & 1 & ,932 & \multirow[t]{2}{*}{ Curah hujan } \\
\hline & $\begin{array}{l}\text { Sig. (2-tailed) } \\
N\end{array}$ & $\begin{array}{r}254 \\
3\end{array}$ & 3 & $\begin{array}{r}, 236 \\
3\end{array}$ & \\
\hline \multirow{2}{*}{$\begin{array}{l}\text { Kelembaban } \\
\text { udara }\end{array}$} & Pearson Correlation & $1,000^{*}$ & ,932 & 1 & \multirow[t]{2}{*}{$\begin{array}{l}\text { Kelembaban } \\
\text { udara }\end{array}$} \\
\hline & $\underset{N}{\text { Sig. (2-tailed) }}$ & $\begin{array}{r}, 018 \\
3\end{array}$ & $\begin{array}{r}, 236 \\
3\end{array}$ & 3 & \\
\hline \multirow{3}{*}{ Suhu udara } & Pearson Correlation &,$- 999^{*}$ &,- 902 &,$- 997^{*}$ & \multirow[t]{3}{*}{ Suhu udara } \\
\hline & Sig. (2-tailed) & ,030 & ,284 & ,048 & \\
\hline & $\mathrm{N}$ & 3 & 3 & 3 & \\
\hline
\end{tabular}

Berdasarkan hasil pengukuran faktor lingkungan (suhu udara, kelembaban, dan curah hujan) dapat diketahui bahwa terdapat hubungan yang signifikan antara persentase serangan dengan kelembaban udara dengan nilai $(F=0,018, p<0.05)$ dan suhu udara dengan nilai $(F=0,030, \quad p<0.05)$, artinya kelembaban udara dan suhu udara merupakan faktor lingkungan yang mempengaruhi persentase serangan PBKo. Sedangkan analisis nilai Pearson Correlation antara kelembaban dan persentase serangan yaitu $r=1,000^{*}$. Hal ini menunjukkan hubungan korelasi antara kelembaban dan persentase serangan yaitu semakin tinggi kelembaban maka akan semakin tinggi persentase serangan PBKo. PBKo sangat menyukai kondisi yang lembab untuk mendukung pertumbuhan dalam metabolisme dan reproduksinya. Hal ini disebabkan karena kelembaban udara merupakan salah satu faktor lingkungan yang mendukung untuk perkembangan PBKo. Ernawati dan Endang (2014) menyatakan bahwa terdapat beberapa faktor yang mempengaruhi perkembangan
PBKo salah satunya adalah naungan yang terlalu lebat mengakibatkan kelembaban tinggi.

\section{KESIMPULAN}

\section{KESIMPULAN DAN SARAN}

1. Perlakuan SiR2K2 merupakan perlakuan terbaik dalam meningkatkan jumlah PBKo terperangkap yaitu dengan rataan 8,83 individu.

2. Perlakuan SuR3K4 merupakan perlakuan terbaik dalam menekan persentase serangan PBKo yaitu dengan rataan sebesar $0,00 \%$.

3. Faktor lingkungan yang berpengaruh terhadap persentase serangan yaitu kelembaban udara dan suhu udara, namun faktor lingkungan tidak berpengaruh nyata terhadap jumlah PBKo terperangkap.

\section{SARAN}

Pengunaan perangkap pada penelitian selanjutnya lebih bervariasi, seperti menggunakan botol perangkap yang bervariasi, dan diukur komposisi asam klorogenat pada daun kopi. 


\section{UCAPAN TERIMA KASIH}

Terima kasih kepada petani Kopi di Sumbul Pak Silalahi dan Bapak Angkat di Sidikalang atas kebaikan hatinya memberikan peminjaman lahan pertanaman kopi sebagai lokasi penelitian. Terima kasih kepada Lembaga Penelitian dan Laboratorium Hama Fakultas Pertanian atas bantuan dana penelitian.

\section{DAFTAR PUSTAKA}

Ernawati, $F$ dan Endang, H. 2014. Perkembangan Hama Pada Tanaman Kopi. Laporan Hasil Penelitian Direktorat jendral perkebunan, Kementerian Pertanian, Jakarta.

Embriani. 2014. Asam Klorogenat Alternatif Atraktan Hama PBK. Laporan Hasil Penelitian. Balai Besar Perbenihan dan Proteksi Tanaman Perkebunan, Surabaya.

Firmansyah AP., Sjam S. dan Dewi VS., 2013. Ekstrak Biji Kopi Sebagai Atraktan Imago Penggerek Buah Kakao (C. cramerella). Laporan Hasil Penelitian. Universitas Hasanuddin, Makassar.

Khairati, N. 2012. Pengaruh Penjualan Kopi Arabika Dalam Bentuk Buah Panen (Cherry Red) Terhadap Ekonomi Petani Kopi Arabika Desa Tanjung Beringin Di Kabupaten Dairi. Skripsi. Fakultas Pertanian. Universitas Sumatera Utara, Medan.

Laila, M. S. I, Nurariaty, A., dan Annie, P. S. 2011. Aplikasi Konsep Pengendalian Hama Terpadu untuk Pengendalian Hama Bubuk Buah Kopi ( $H$. hampei). J. Fitomedika. 7 (3): 162 - 166.

Malau, S. 2010. Serangan Penggerek Buah Kopi dan Dampaknya di Samosir. Laporan Hasil Penelitian. Badan Penelitian dan Pengembangan Provinsi Sumatera Utara. Medan.

Nugroho, B. A. 2015 Pengendalian Penggerek Buah Kopi (H. hampeI) Pada Tanaman Kopi Dengan Menggunakan Feromon. Laporan Hasil Penelitian. Balai Besar Perbenihan dan Proteksi Tanaman Perkebunan, Surabaya.
Renwick, J.A.A and F.S. Chew. 1994. Oviposition Behavior In Lepidoptera. Annu. Rev. Entornot. Vol. 39:377-400.

Siregar, A. Z. 2016. Bioecology of $H$. hampeii in Coffee Plantation in Sumbul and Sidikalang District, Northenof Sumatera Indonesia. Internasional Journal of Advanced Research. 4 (11) : 20512058.

Syahnen, A., Yenni, dan Ida, R.T.U.S. 2010. Rintisan Metode Pengamatan Hama Penggerek Buah Kopi (Hypothenemus hampei Ferr.) di Kabupaten Dairi Propinsi Sumatera Utara. Laboratorium Lapangan Balai Perbenihan dan Proteksi Tanaman Perkebunan. Medan

Wiryadiputra, S. 2014. Pola Distribusi Hama Penggerek Buah Kopi (Hypothenemus Hampei Ferr.) pada Kopi Arabika dan Robusta. Jurnal Pelita Perkebunan, 30 (2) : 123-136. 


\section{J U R N A L AGROTEKNOLOGI Journal of Agrotechnology}

RESPON PERTUMBUHAN DAN HASIL TANAMAN SELEDRI TERHADAP NUTRISI DAN NAUNGAN MENGGUNAKAN SISTEM HIDROPONIK RAKIT APUNG

Growth and Production Response of Celery on nutrion and shading rate Using Floating Hydroponics System

Mercy Bientri Yunindanova, Linayanti Darsana dan Ardianto Pradana Putra

PERTUMBUHAN PADI GOGO PADA MEDIUM ULTISOL DENGAN APLIKASI BIOCHAR DAN ASAP CAIR

Application of Biochar dan Liquid Smoke to the Growth of Upland Rice (Oryza sativa. L) on Ultisol Medium

John Ivan Ndruru, Nelvia dan Adiwirman

PENGGUNAAN ATRAKTAN ASAM KLOROGENAT PADA PERANGKAP DALAM MENGENDALIKAN PBKo (Hypothenemus hampei Ferr.) PADA PERKEBUNAN KOPI DI KABUPATEN DAIRI

The Utilization of Chlorogenic Acid Attractant in Traps to Controlling PBKo (Hypothenemus hampei Ferr.) on Coffee Plantation in Dairi

M Mustain Aziz, Ameilia Zuliyanti Siregar dan Hasanuddin

SELEKSI BEBERAPA GENOTIPE PADI SAWAH LOKAL (Oryza sativa L.) TERHADAP CEKAMAN KEKERINGAN MENGGUNAKAN POLYETHYLENE GLYCOL (PEG) PADA FASE PERKECAMBAHAN

Selection of Many Genotypes the Rice Paddy Local (Oryza sativa L.) Against Drought Stress Using Polyethylene Glycol (PEG) in the Phase of Germination

Shinta Sawitri, Rabbana Saragih dan Ervina Ariyanti .....

ISOLASI BAKTERI Rhizobium DARI TUMBUHAN LEGUMINOSA YANG TUMBUH DI LAHAN BERGAMBUT

Isolation of Rhizobium From Legume That Growth In Peatland

R. Danang Suto Pamungkas dan M. Irfan

UJI PESTISIDA NABATI SIRIH HUTAN (Piper aduncum L.) TERHADAP LARVA KUMBANG TANDUK Oryctes rhinoceros L. PADA TANAMAN KELAPA SAWIT

Test of Piper Bettle Forest (Piper aduncum L.) Against The Larvae Horn Beetle Oryctes rhinoceros L. On Palm Oil Crop

Joni Irawan, Rusli Rustam dan Hafiz Fauzana. 